\title{
Twitter Verilerinin Uzaktan Eğitimdeki Ölçme ve Değerlendirme Etkisi
}

\author{
Tuğba Güler* ${ }^{*}{ }^{1}$
}

\begin{tabular}{|c|c|}
\hline Anahtar Sözcükler & $\ddot{\mathbf{O} z}$ \\
\hline Uzaktan Eğitim & Dünyada sağlik sektöründe ve daha birçok alanda dengeleri değiştiren Covid-19 virüsü, eğitim \\
\hline Ölçme & sektörünü de olumsuz yönde etkilemiştir. Öyle ki eğitmenler ve öğrenciler için mevcut eğitim \\
\hline Değerlendirme & sisteminin daha verimli devam edebilmesi için bu alanda yenilikler denenmesine ve bu yeniliklerin \\
\hline Twitter & de kullanılmasına sebep olmuştur. Bahsedilen yeniliklerin başında gelen ve Covid-19 sürecinde \\
\hline RapidMiner & $\begin{array}{l}\text { tüm dünya genelinde yaygınlaşan uzaktan eğitim sistemi bir diğer adıyla çevrimiçi eğitim sistemi, } \\
\text { günümüzde kullanılan tablet, telefon gibi mobil cihazların yardımıla birlikte her yönden }\end{array}$ \\
\hline Makale Hakkında & $\begin{array}{l}\text { öğrencilere erişimi ve eğitimi daha rahat sürdürebilme imkânı vermiştir. Öğrencilerin yapılan } \\
\text { eğitim sonucunda bilgi seviyelerinin belirlenmesini amaçlayan ölçme ve değerlendirme, uzaktan }\end{array}$ \\
\hline Gönderim Tarihi & eğitim süresince çevrimiçi olan farklı birkaç test formatı ile yürütülmektedir. Sosyal medya ve \\
\hline 07 Şubat 2021 & $\begin{array}{l}\text { internet ise günümüz kullanım popülaritesinin yanı sıra uzaktan eğitim periyodunda da öğretmen } \\
\text { ve öğrencilere kaynak ve iletișim açısından büyük kolaylıklar sağlamaktadır. Bu çalışma, popüler }\end{array}$ \\
\hline Kabul Tarihi & sosyal medya örneklerinden biri olan Twitter'da uzaktan eğitim çatısı altındaki ölçme \\
\hline 14 Aralık 2021 & değerlendirme değişkenlerinin analizini gerçekleştirmektedir. Yapılan bu analizler, bir veri \\
\hline Yayın Tarihi & madenciliği yazılımı olan RapidMiner platformu kullanılarak gerçekleştirilmiş̧tir. Analizler, eğitim \\
\hline 24 Aralık 2021 & $\begin{array}{l}\text { alanında en trend olan başlıklar hakkında fikir verme ve alanyazına uygun bir yöntem sunma amacı } \\
\text { gütmektedir. Analizlerin sonucunda, Twitter kullanımının uzaktan eğitim döneminde ölçme ve } \\
\text { değerlendirme acısından en cok ortaöğretim düzevinde yavgın olduğu anlașllmıstır. }\end{array}$ \\
\hline
\end{tabular}

Makale Türü

Araştırma Makalesi

\section{Assessment and Evaluation Effects of Twitter Data on Distance Education}

Keywords
Distance Education
Assessment
Evaluation
Twitter
RapidMiner

Article Info

Received

February 07, 2021

Accepted

December 14, 2021

Published

December 24, 2021

\begin{abstract}
Changing the balances in the world, Covid-19 has also affected the education sector and caused innovations to be tried and used in the current education system for educators and students. The distance education system, which is one of these innovations and the common usage around the world in the Covid-19 period, has given students the opportunity to continue access and education more comfortably with the help of today's mobile devices. Assessment and evaluation, which aims to determine the knowledge level of students as a result of the education, is carried out with several different test formats online during distance education. Social media and internet provided great convenience to teachers and students in terms of resources and communication during the distance education period. This study performs the analysis of measurement and evaluation variables under the umbrella of distance education on Twitter, one of the popular social media examples. These analyzes were carried out using the RapidMiner platform, which is a data mining software. The analyzes aim to give an idea about the most trending topics in the field of education and to present a method suitable for the literature. As a result of the analysis, it has been understood that the use of Twitter is most common at the secondary education level in terms of measurement and evaluation in the distance education period.
\end{abstract}

Article Type

Research Paper

Atıf: Güler, T. (2021). Twitter verilerinin uzaktan eğitimdeki ölçme ve değerlendirme etkisi. Bilgi ve İletişsim Teknolojileri Dergisi, 3(2), 196-211. https://doi.org/10.53694/bited.876319

Cite: Guler, T. (2021). Assessment and evaluation effects of Twitter data on distance education. Journal of Information and Communication Technologies, 3(2), 196-211. https://doi.org/10.53694/bited.876319

\footnotetext{
*Sorumlu Yazar/Corresponding Author tugbaozturkguler@gmail.com

${ }^{1}$ M.Sc. Student, Bartin University, Computer Technology and Information Systems, Bartin/Turkey, tugbaozturkguler@gmail.com, 


\section{Introduction}

With the new regulations, the online training system is carried out in software-based online meeting environments as virtual classrooms. Today, every individual (academician, teacher, student, etc.) with the Internet infrastructure can simultaneously teach their lessons in virtual classrooms with a video and an audio. In addition, students can participate in their lessons visually and audibly through the used virtual classrooms. While educators and students share interactively with the whiteboards or screen sharing tools found in the online meeting software, students can simultaneously ask their questions and get the necessary answers from the instructors. The online courses can be recorded and can be watched or reviewed as course material by students outside of course hours.

Many teachers, who did not have enough training on how to deal with such a problem during their employment, were caught unprepared for this process (Dubey \& Pandey, 2020). Instructors in most places are expected to use their entrepreneurial skills and to find solutions to the problem on their own without getting enough support. Teachers with limited skills in providing distance education face difficulties in performing effectively alone during this period. Apart from differences between teachers, the resources of the school, students' access to technological tools and their application skills have a significant effect on how teachers spend their distance education. The need for all this infrastructure and the system that should be taken into consideration for the training to be taken is how the measurement and evaluation should be done.

The exams used for assessment and evaluation in the distance education programs of universities around the world are conducted entirely on the Internet. During the Covid-19 pandemic, distance education is carried out to determine whether the knowledge, skills and attitudes expected from students have improved, and if so, to what extent (Chick, Clifton, Peace, Propper, Hale, Alseidi, \& Vreeland, 2020). Assessment types in distance education also reveal the purposes of determining the learning deficiencies of the evaluations, determining the interests and abilities of the students, evaluating the success of the students, evaluating the effectiveness of the teaching and evaluating the curriculum (Astin, 2012). Instructors are required to make evaluations that measure learning activities with tests and exams to determine teaching goals.

Since 2020, COVID-19 virus, which still affects people's lives, has forced teachers using online learning devices and networking. With this motivation, the mechanism of learning for students is changed in very short time as online distance learning. When students are in online lessons, there are different notifications coming from social media and messaging applications to be able to distract the attention of the students.

While some may hesitate to deviate from traditional educational practices, it is important to prioritize the student's needs and therefore ensure that they are taught in a way that maximizes their potential and learning. As more social media platforms continue to be introduced, the Internet is evolving and should therefore be used as a tool to assist the educational process. By proving itself as an invaluable tool and information pool, it is a technological infrastructure where measurement and evaluation can be actively done. In addition, it makes it possible to make categorical and detailed analyzes with detailed information about the measurement and evaluation techniques.

Today, many different tools with which data analysis can be made easily provide services to people via the internet. RapidMiner, which is widely used in fields such as data mining, data analysis and machine learning, is a kind of 
software platform that includes a graphical user interface. This software, which passes the data to be analyzed through many different methods such as data preprocessing techniques and model creation operators, has been involved in many studies in the literature (Das, Sharma, Natani, Khare, \& Singh, 2017; Kunnakorntammanop, Thepwuttisathaphon, \& Thaicharoen, 2019; Sinoplu \& Y1lmaz, 2020; Udayakumar, Senadeera, Yamunarani, \& Cheon, 2018). In this study, RapidMiner software was used in the analysis process of Twitter data.

In this research project developed in the light of all this information, it is planned to make categorical data analysis and the effects of Twitter, one of the social media platforms in distance education, in terms of measurement and evaluation techniques in the Covid-19 period.

The aim of the research is to analyze the relevant big twitter data, which is too comprehensive to be analyzed with manual approaches, and to present a method suitable for the literature. At the same time, it is aimed to contribute to education about the most up-to-date Twitter data under the title of measurement and evaluation.

\section{Method}

In this study, we examine the analysis of data on Twitter from social media platforms and the use of assessment and evaluation variables in the distance education structure during the pandemic period that has recently taken place in our lives. First of all, we retrieve Twitter data using business structures created through RapidMiner data mining and analysis software. The current Twitter data (tweets) are created with the query texts "exam, project, measurement, evaluation, success, study, etc." which are different measurement and evaluation variables.

We use the RapidMiner Twitter Search operator for the process of obtaining current data from Twitter social media platform. The query text we have created with the Twitter search tool is obtaining all recent data regarding "distance education", consisting of Turkish tweets. All data received can be saved to Microsoft Excel file from the output unit of the Twitter search tool with the "Write Excel" tool in the RapidMiner software and hosted locally in our system. After saving Twitter data to our system, we need to explain all the steps created in RapidMiner software in order to make our analysis on all data.

First of all, we examine Twitter data using two separate processes. In order to create these transaction processes, we create them with the help of the RapidMiner tools called multiply. The data set obtained after this process can contain more than one similar copies. In order to clean the duplicates, the Remove Duplicates operator, located in the first process band, eliminates the similarity problems in the data set by deleting the copies according to the text contained in the tweet data. After editing the copy data, we use RapidMiner's Nominal to Text operator in order to ensure that the texts in the tweets are in text format, or to clean the symbolic structures that are not in any text format used. After editing the Twitter texts and making the data manageable, the process to be done is to separate the words in the texts from each other and determine the sub-texts or meaningful words in the data set. The "Process Documents from Data" operator will start the desired subprocess among the word snippets to be created within the texts and convert the texts into certain string elements.

In the process of "Documents from Data," the "Tokinize" operator is used first to turn the sentence structures into word strings over the texts in the data set after the operation of the previous operator. We try to limit the size of each word fragment to 4-25 characters with the "Filter Tokens (by Length)" while converting the "Transform Cases - lowercase" operator to lower case structures in order to avoid any difference. Finally, through the "Filter 
Stopwords (Dictionary)" operator, we have filtered words from our dataset through the library (Dictionary) that we have created that will not be considered as semantic data for data analysis such as connectors, stop state notifications and similar data. In the process here, all library members were created by ourselves, from the dictionary of the Turkish Language Institution, due to the lack of Turkish language support in the RapidMiner software.

After the operations are completed, we complete the operations of the "Process Documents from Data" operator and transmit the filtered data set to the "WordList to Data" operator and create all the word snippets as a structured dataset.

Based on retreived data and created our dataset, we show the usage rates of the words "measurement" and "evaluation" used in the measurement and evaluation infrastructure in the distance education process in Twitter posts. When we examine the measurement and evaluation variables in the distance education process, the common words in the posts made as tweets are stated as "enrichment, preparation, continuation, exams and questionnaire". Among these words, we can reveal the situation that it is widely used in the distance education assessment and evaluation system in the questionnaire variable specified in the distance education process.

\section{Discussion and Conclusion}

In this research, we analyze the effects and rates of words in tweets created by users about the measurement and evaluation infrastructure in distance education during the pandemic period on the Twitter social media platform by using RapidMiner. In the light of all analyzes and categorical data, we can see that word groups in tweets have high usage. Based on these high usage rates, as one can see, the measurement and evaluation infrastructure in distance education is more common in the Twitter platform for the secondary education level. 


\section{Uzaktan Eğitim Sistemi}

Uzaktan eğitim sistemi öğrencinin istediği yerde ve şekilde, okula gitmeden, kaynakların kaydedilip sonradan tekrar kullanabileceği, çağımıza uygun ve reformcu bir yapıdır (Sherry, 1995). Uzaktan eğitim, öğrenci ve öğretenin eğitim kurumunda bulunma gereksinimi olmadan eş ya da ayrı zamanlı şekilde bilgisayar, tablet veya telefon gibi günümüz teknoloji araçlarıyla derslerin yürütüldüğü, çağdaş bir eğitim düzenidir (Valentine, 2002).

Yeni düzenlemeler ile çevrimiçi eğitim sistemi gerçek sınıf olmayan (sanal sınıflarda) yazılım tabanlı çevrimiçi toplantı ortamlarında gerçekleştirilmektedir. Günümüzde internet altyapısına sahip her bir birey (akademisyen, öğretmen, öğrenci, vb.) hali hazırda bulunan çevrimiçi sistemdeki sanal sınıflarda eş zamanlı olarak derslerini görüntülü ve sesli olarak anlatabilir. Ayrıca öğrenciler de derslerine, kullanılan sanal sınıflar aracılığıyla görüntülü ve sesli olarak katılabilmektedirler. Etkileşimli olarak eğitimciler ve öğrenciler çevrimiçi toplantı yazılımlarında bulunan yazı tahtaları veya ekran paylaşım araçları ile paylaşımlarını yaparlarken, öğrenciler eş zamanlı olarak sorularını sorarak eğitmenlerden gerekli yanıtlarını alabilirler. Çevrimiçi olarak yapılan dersler kayıt altına alınarak, öğrenciler tarafından ders saatleri dışında çevrimdışı olarak tekrardan ders materyali halinde izlenebilir veya incelenebilir.

\section{Pandemi Döneminde Uzaktan Ĕ̆itim}

Günümüzdeki korona virüs salgını sebebiyle, dünya genelinde okullardaki tüm seviyedeki eğitimler durduruldu. Ancak birçok ülkede eğitim tamamen durdurulmamış, çevrimiçi olarak ülkeler ve okullar internet altyapısını kullanan uzaktan eğitim uygulamalarına yönelmiştir. Teknolojik cihazların kullanımı sayesinde öğrenciler eğitimlerine ara vermeden hızlı bir şekilde yeni sistemde uzaktan eğitime başlamıştır (Bozkurt \& Sharma, 2020). Okulların kapanmasının ardından birçok ülke uzaktan eğitime çok hızlı başlamıştır. Pandemi dönemi süresince öğreticilerin de öğrencileri eğitim açısından desteklemeleri ve çevrimiçi eğitime dâhil olmaları beklenmiştir, fakat birçok ülkede öğretmenler öğrencileriyle iletişime geçmek istese bile öğretmenlerin "uzaktan eğitim” konusunda eğitim gördükleri ülke sayısı çok sınırlı kalmıştır; Avrupa ve Asya'da, ülkelerin yalnızca \%20 ile \%30'u öğretmenlere çevrimiçi eğitim konusunda eğitim vermektedir (Adedoyin \& Soykan, 2020).

Çalıştıkları süre zarfında yaşanan bu şekildeki bir sorunla nasıl başa çıkılacağı konusunda yeterli eğitim almamış, daha önce hiç bu tür deneyime sahip olmayan birçok öğretmen bu sürece hazırlıksız yakalanmıştır (Dubey \& Pandey, 2020). Çoğu yerdeki eğitmenlerin girişimcilik yeteneklerini kullanmaları ve kendi başlarına soruna çözüm üretmeleri beklenir fakat öğretmenler yeterince destek alamamaktadır. Uzaktan eğitim sağlama konusunda sınırlı becerilere sahip olan öğreticiler, bu dönemde yalnız olarak etkin bir şekilde gerçekleştirmede zorluklarla karşılaşmaktadır. Öğreticilerin arasındaki farklılıkların dışında, okulun kaynakları, öğrencilerin teknolojik araçlara erişimi ve uygulama becerileri, öğretmenlerin uzaktan eğitimlerini ne şekilde harcadıkları üzerinde önemli bir etkiye sahiptir. Tüm bu altyapıya duyulan ihtiyaç ve alınacak eğitim için diğer göz önünde bulundurulması gereken sistem de ölçme ve değerlendirmenin nasıl yapılması gerektiğidir. 


\section{Uzaktan Eğitimde Öıçme ve Değerlendirme Nasıl Yapılmaktadır?}

Üniversitelerin uzaktan eğitim programlarında ölçme ve değerlendirme için kullanılan sınavlar tamamen internet üzerinden yapılmaktadır. Uzaktan eğitim Covid-19 salgını döneminde, ölçme ve değerlendirme öğrencilerden beklenen bilgi, beceri ve tutumların gelişip gelişmediğini, geliştiyse hangi ölçüde geliştiğini belirlemek amacıyla yapılır (Chick, Clifton, Peace, Propper, Hale, Alseidi, \& Vreeland, 2020). Uzaktan eğitimde değerlendirme türleri aynı zamanda yapılan değerlendirmelerin öğrenme eksikliklerinin saptanması, öğrencilerin ilgi ve yeteneklerinin saptanması, öğrencilerin başarısının değerlendirilmesi, öğretimin etkinliğinin değerlendirilmesi ve öğretim programının değerlendirilmesi amaçlarını da ortaya koyar (Astin, 2012). Eğitmenlerin testler ve sınavlarla öğretim hedeflerini belirlemek için öğrenme etkinliklerini ölçtüğü değerlendirmeler yapmaları gerekmektedir. Test ve ölçüm teorisi ve bunların analizi üzerine, eğitmenler tarafından planlama, geliştirme ve test öğelerinin yazılması hakkında çok az ayrıntı içeren çok sayıda literatür vardır (Osterlind, 2002). Uzaktan eğitim veya çevrimiçi öğrenmede, değerlendirmeler genellikle çevrimiçi olarak gerçekleştirilir; bu nedenle, hile yapmayı düzenlemeyi ve kontrol etmeyi imkânsız hale getirmektedir (Arkorful \& Abaidoo, 2015). E-öğrenme ile uygulanabilen birkaç öğrenci test formatı vardır ve Osterlind'e (2002) göre, bu tür geliştirilmiş test formatları, yapılandırılmış yanıt, performansa dayalı formatlar, cümle tamamlama veya kısa yanıt, eşleş̧irme, doğru-yanlış metotlarını içerir. Flaherty (2020), bu salgın sırasında notlandırma sistemlerinin önemli ölçüde değiştirilmesinin güçlü bir savunucusu olduğunu, çünkü öğrenenlerin iddiasının düşünülemez olduğunu eklemiştir. Covid-19 salgını, değerlendirmeyi daha karmaşı hale getirirken, çevrimiçi öğrenme yoluyla aynı öğrenme deneyimlerini ve şanslarını elde edebilir.

\section{Sosyal Medyanın Uzaktan Eğitimdeki Etkisi}

2020 yllında başlayan ve halen devam etmekte olan koronavirüs 2019 (COVID-19) salgını, eğitimcileri ağ iletişimini içeren uzaktan eğitim araçlarını kullanmaya zorlayarak öğrenmede bir paradigma değişikliğine neden olmuştur. Birkaç ay içinde, bu değişim milyonlarca öğrencinin öğrenme şeklini değiştirmiştir. Çevrimiçi eğitim ortamı, gerekli sosyal mesafenin olduğu bir dönemde öğrenciler ve öğretmenler arasındaki bazı boşlukları kapatmayı başarsa da internet tabanlı eğitim kendi doğasında olan engellerle karşı karşıyadır. Çevrimiçi dersler sırasında, öğrenciler genellikle çevrimiçi sosyal medya ve sürekli uğultulu bildirimler gibi dikkat dağıtıcı şeylerle boğuşurlar. Bu dikkat dağıtıcı unsurlar, WhatsApp mesajlarını kontrol etmeyi ve Facebook, Twitter ve Instagram gibi sosyal ağları ziyaret etmeyi içerir. Fiziksel bir sınıf ortamında geleneksel "yüz yüze" (face to face) öğretimin yokluğunda, öğrenciler öğretmenlerin ve akranların fiziksel varlığından kaynaklanan açık motivasyon ve gizli ilhamdan mahrum kalırlar.

Yüz yüze öğrenmenin en iyisi gibi çevrimiçi öğrenmenin de en iyisi, öğrencinin aktif katılımını gerektirir (Anderson, 2008). Öğrenciler, aktarılan bilginin pasif alıcıları olmaktan ziyade, öğrenme sürecinde aktif katılımcılardır. Öğrenciler (sadece eğitmen değil), öğrenme ortamının yaratılmasına yardımcı olur. Öğretim tamamen tek yönlü iletişim değil, çoktan çoğa iletişimin olduğu bir öğrenme ortamı ile ilgilidir. İdeal olarak, öğrencilerin eğitmenden öğrendikleri kadar birbirlerinden de öğrenmeleri beklenir. Bu durum, öğrenme etkinliklerini yönetir ve öğrenmeyi kolaylaştırır.

Liu ve diğerleri (2009), literatürde incelendiği üzere, yükseköğretimde en sık kullanılan sosyal medya 
teknolojilerini bloglar, podcastler, sosyal ağlar ve sanal ortamlar olarak bulmuşlardır. Hovorka ve Rees (2009), bilgi sistemleri derslerinde bir dizi sosyal medya teknolojisinin kullanımını incelemiştir. Sosyal medyayı kurslara dâhil etmek, onları daha ilginç ve hatta eğlenceli hale getirmeye yardımcı olmakla kalmaz, aynı zamanda öğrencilere iletişim, iş birliği, topluluk, yakınsama ve yaratıcılık gibi değerli ve yaygın işyeri becerilerini öğrenebileceklerini öğretebilir.

Bununla birlikte, öğrenciler sosyal medyayı kullanmaya ve çevrimiçi bilgi tüketmeye zaten aşina olduklarından, doğal olarak uzaktan eğitim altyapısını da bilirler. Bu nedenle, daha fazla kurum sosyal medyayı öğretme ve öğrenme süreçlerine dâhil etmeye ve benimsemeye başlar. Öğrenciler, oturup bol miktarda metin okumak zorunda kalmak yerine videolar ve diğer ortamlar aracılığıyla öğrenebilirler. Yalnızca farklı öğrenme tarzlarına hitap etmekle kalmayan, aynı zamanda kendilerine uygun ve aşina oldukları bir şekilde öğrenmelerini sağlayan öğrenme esnekliğine sahip olabilmektelerdir.

Sosyal medya ve İnternet, öğrencilerin kaynaklara ve rehberliğe erişmeye devam ederken kendilerini bir toplulukta daha dâhil hissetmelerini de mümkün kılar. Sosyal medya, genellikle insanlarla iletişim kurmanın veya soruların yanıtlanmasının en hızlı yoludur, bu nedenle bilgileri konumdan bağımsız olarak erişilebilir kılar. Örneğin, güncel olaylarla ilgili haberler, televizyon istasyonları bunu haber yapma şansı bulamadan sosyal medyaya hızla yayılabilir. Sosyal medya anlıktır ve gerçek zamanlı iletişime izin verir, neredeyse insanlarla günlük etkileşimlerimizi taklit eder (Asur \& Huberman, 2010). Bu nedenle, eğitimde kullanımı ancak öğrenmeye yardımcı olmanın ve öğrenci için ortak bir deneyim yaratmanın bir yolu olarak algılanabilir. Öğretmenler, içeriği ve ilgili materyalleri öğrencilerle gerçek zamanlı olarak paylaşabilir ve etkileşimler, sınıf ortamında olduğu kadar sınırlı değildir.

Ayrıca, ögrencilerin daha fazla soru sormalarına ve kendi anlayışlarını netleştirmelerine olanak tanır; bu, kendilerine öğretilen şeyleri düşünmek için zaman olmadığında, sınıfta genellikle zor olan bir şeydir. Sosyal medya, öğretmenler ve öğrenciler arasındaki iletişimi bile geliştirir çünkü hiçbir tarafın bir e-posta yazmak için oturması gerekmez. Sosyal medyaya telefonlardan ve tabletlerden erişilebilir, bu da birbirlerine yanıt vermeyi kolaylaştırır ve böylece öğrenci ve öğretmen arasındaki genel etkileşimi geliştirir. Bu, öğrencilerin içeriği daha iyi anlayabilmelerini, ancak yine de inisiyatiflerini kullanmalarını ve sorgulama yoluyla daha kritik hale gelmelerini sağlar.

Çevrimiçi toplulukların varlığ 1 ve erişilebilirliği, öğrencilerin cesaretlendirilmiş ve motive olmuş hissetmelerini sağlamanın ayrılmaz bir parçası olan destek sağlamaya da yardımcı olabilir. Akranların fiziksel varlığı olmadan, öğrencilerin heves eksikliğiyle geride kalması kolaydır. Sosyal medya, öğrencilerin bir destek ağına sahip olmasını ve başkalarıyla etkileşimini sürdürmesini mümkün kılar (Selwyn \& Stirling, 2016).

Eğitimin çehresi değiş̧meye devam ederken, kurumlar müfredatlarını yeni nesil öğrencilere hitap edecek şekilde geliştirmeye devam etmenin yollarını bulmak zorunda kalmıştır (Bahasoan, Ayuandiani, Mukhram, \& Rahmat, 2020). Bazıları geleneksel eğitim uygulamalarından sapmakta tereddüt etse de öğrencinin ihtiyaçlarını önceliklendirmek ve bu nedenle onların kendi potansiyellerini ve öğrenmelerini en üst düzeye çıkaracak şekilde öğretilmelerini sağlamak önemlidir. Daha fazla sosyal medya platformu tanitılmaya devam ederken, internet gelişmektedir ve bu nedenle eğitim sürecine yardımcı olacak bir araç olarak kullanılmalıdır. Kendisini paha 
biçilmez bir araç ve bilgi havuzu olarak zaten kanttlayarak ölçme ve değerlendirmenin de aktif olarak yapılabileceği bir teknolojik altyapı olmaktadır. Ayrıca, ölçme değerlendirme teknikleriyle ilgili detaylı bilgilendirmeleriyle kategorisel ve detaylı analizlerinin yapılmasını da mümkün kılmaktadır.

Veri analizlerinin yapılabildiği birçok farklı araç günümüzde İnternet aracılığılla kişilere kolayca hizmet sunmaktadır. Veri madenciliği, veri analizi ve makine öğrenmesi gibi alanlarda yaygın olarak kullanılan RapidMiner, grafiksel kullanıcı ara yüzünü içeren bir çeşit yazılım platformudur. Analiz edilecek veriyi, veri önişleme teknikleri ve model oluşturma operatörleri gibi farklı birçok yöntemden geçiren bu yazılım, alanyazında birçok çalı̧̧mada yer almıştır (Das, Sharma, Natani, Khare, \& Singh, 2017; Kunnakorntammanop, Thepwuttisathaphon, \& Thaicharoen, 2019; Sinoplu \& Y1lmaz, 2020; Udayakumar, Senadeera, Yamunarani, \& Cheon, 2018). Bu çalışmada da Twitter verilerini analiz surecinde RapidMiner yazılımından yararlanılmıştır.

Tüm bu bilgiler 1şığında geliştirilen bu araştırma projesinde Covid-19 döneminde uzaktan eğitimde sosyal medya platformlarından Twitter'ın ölçme değerlendirme teknikleri açısından etkileri ve kategorisel olarak veri analizlerinin yapılması planlanmaktadır.

Araştırmanın amacı, analizi manuel yaklaşımlarla yapılamayacak kadar geniş kapsamlı olan ilgili büyük twitter verilerinin analizini gerçekleştirip alanyazına uygun bir yöntem sunmaktır. Aynı zamanda en güncel Twitter verileri hakkında eğitime ölçme değerlendirme başlığı altında katkı sağlama amaçlanmıştır.

\section{Yöntem}

$\mathrm{Bu}$ araştırmada, yakın zamanda hayatımızda yer edinmiş olan pandemi sürecindeki uzaktan eğitim yapılanmasında sosyal medya platformlarından Twitter üzerindeki verilerin analizini ve ölçme değerlendirme değişkenlerinin kullanımını inceliyoruz. Öncelikle Twitter verilerini RapidMiner veri madenciliği ve analizi yazılımı aracıllğıyla oluşturulan iş yapılarını kullanarak kayıt altına alıyoruz. Kayıt altına alınan güncel Twitter verileri (tweet) oluşturulan sorgu (query) metinleri ile farklı ölçme değerlendirme değişkenleri olan "sınav, proje, ölçme, değerlendirme, başarı, çalışma, vb.” kelimeler için analiz ediliyor. Tüm bu işlemlerin RapidMiner yazılımı kullanılarak oluşturulması sırasıyla alt başlıklar altında anlatılacaktır.

\section{Veri Seti}

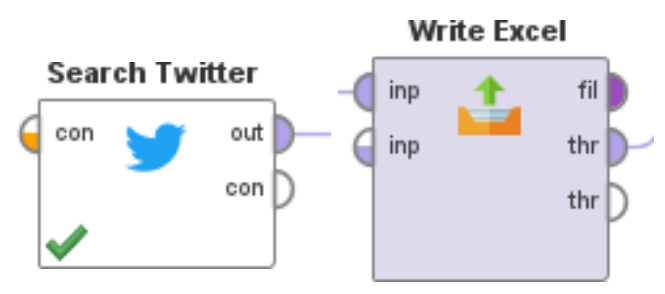

Şekil 1. RapidMiner Twitter Arama Aracı ile Verileri Kaydetme

Güncel verilerin Twitter sosyal medya platformundan elde edilmesi işlemi için Şekil 1'de görüldüğü gibi RapidMiner Twitter Arama operatörünü kullanıyoruz. Twitter arama aracı ile birlikte oluşturduğumuz sorgu metni "uzaktan eğitim" ile ilgili tüm yakın zamandaki verileri Türkçe tweetlerden oluşacak şekilde elde ediyoruz. Alınan tüm veriler Twitter arama aracının çıkış biriminden Microsoft Excel dosyasına RapidMiner yazılımında bulunan 
"Write Excel” aracı ile kaydedilerek lokal olarak kendi sistemimizde barındırılabiliyor.

\section{Verilerin Analizi}

Twitter verilerini bir önceki bölümde anlatıldığı gibi sistemimize kaydettikten sonra tüm veriler üzerinde analizlerimizi yapabilmek amacıyla RapidMiner yazılımında oluşturmamız gereken tüm işlem adımlarını sırasıyla anlatmamız gerekmektedir.

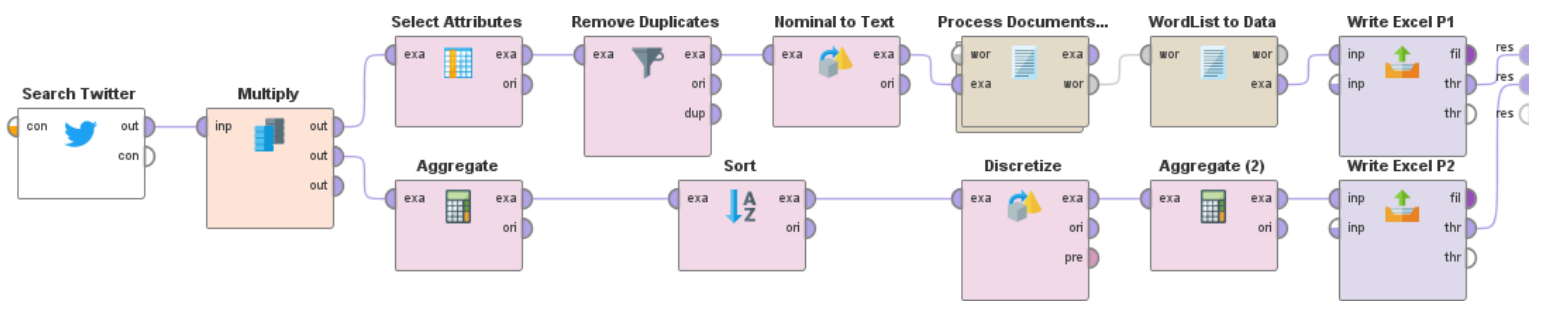

Şekil 2. RapidMiner Twitter Veri Analizi İşlemler

Öncelikle Şekil 2'de görüldügü üzere Twitter verilerini iki ayrı işlem süreci (process) kullanılarak inceliyoruz. Bu işlem süreçlerini oluşturmak için RapidMiner araçlarından çoklandırıcı (multiply) yardımıyla oluşturuyoruz. Bu araç bize aynı anda eş zamanlı olarak Twitter verilerinin farklı analizlerini yapmamıza yardımcı oluyor.

Çoklandırıcı aracı ilk olarak Şekil 2'de üst satırda görünen birinci işlem sürecindeki veri analizini oluştururken "Değişkenlerin Seçilmesi (Select Attributes), Kopyaların Silinmesi (Remove Duplicates), Yazı Gösterimi (Nominal to Text), Verilerden Döküman İşlemi (Process Documents from Data), Kelime Listesi Oluşumu (WordList to Data) ve Microsoft Excel'e Kaydet (Write Excel P1)” operatörlerini sırasıyla kullanıyoruz. Select Attributes operatörü verilerin alınması işleminde oluşturulan tüm nitelik değişkenlerinden bir alt küme seçmemizi sağlamaktadır. Alt küme, öznitelikler parametresi olarak belirtilen kısıtlama biriminde tanımlanarak belirtilir. Bu işlemi oluşturmak için bir önceki operatörün çıkış bağlantı noktası Select Attributes operatörünün giriş bağlantı noktasına bağlanarak istenilen Twitter verilerinde bulunan "From-User, Id, To-User, Tweet Metni (Text)" nitel başlıkları seçilir. $\mathrm{Bu}$ işlemden sonra elde edilen veri kümesi içerisinde birden fazla benzer kopyalar barındırabilmektedir. Bunun sebebi farklı kullanıcıların diğer kullanıcıların Twitter platformunda paylaşmış oldukları tweetleri kendilerinin de üzerinde herhangi bir değişiklik yapmadan tekrar (retweet) paylaşmalarındandır. Oluşan kopyaların temizlenebilmesi için ilk işlem süreç bandında bulunan Remove Duplicates operatörü tweet verilerinin içerisinde barındırdığı metin (text) verisine göre kopyaları silerek veri setindeki benzerlik sorunlarını ortadan kaldırmaktadır. Kopya veriler düzenlemesi yapıldıktan sonra tweetlerdeki metinlerin yazı formatında olmasının garanti halinde olması veya kullanılan herhangi bir yazı formatında olmayan simgesel yapıların temizlenebilmesi için RapidMiner'ın Nominal to Text operatörünü kullanmaktayız. Nominal to Text operatörü, tüm özniteliksel metin parçalarını bir dize olarak dönüşüm yapar ve her bir yeni gösterim değeri dizenin bir değeri olarak belirlenmektedir. Twitter metinlerinin düzenlenmesi ve verilerin işlenebilir hale getirilmesinden sonra yapılacak işlem, metinlerdeki kelimelerin birbirinden ayrıştırılarak alt metinlerin veya anlamlı kelimelerin veri kümesi içerisinde belirlenmesidir. "Process Documents from Data" operatörü metinler içerisinde oluşturulacak kelime parçacıkları arasında istenilen alt işlem sürecini başlatarak Şekil 3'te görüldüğü gibi metinleri belirli dize elemanları olarak dönüştürecektir. 


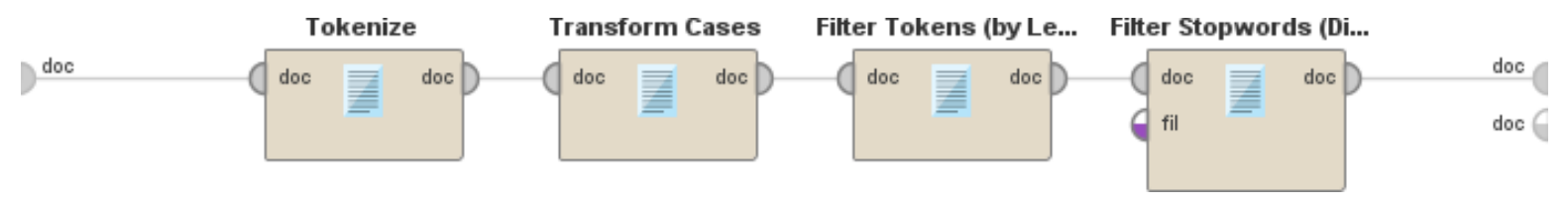

Şekil 3. "Process Documents from Data" operatörünün alt işlem süreci

Şekil 3’te görüldüğü üzere, önceki operatörün işlemi sonrası veri kümesinde bulunan metinler üzerinden cümlesel yapıları kelime dizisi haline getirmek için ilk olarak "Tokenize" operatörü kullanılır. Oluşan kelime birimlerinin hepsini herhangi bir farklılık olmaması için küçük harfli yapılara "Transform Cases - lowercase" operatörü dönüştürürken "Filter Tokens (by Length)" ile her bir kelime parçasının boyutlarını 4-25 karakter arasında sınırlamaya çalışırız. Son olarak da "Filter Stopwords (Dictionary)" operatörü aracılığıyla veri kümemizde bulunan bağlaç, durma durumu bildirimleri ve benzeri veri analizi için anlamsal veri olarak kabul edilmeyecek kelimeleri oluşturduğumuz kütüphane (Dictionary) aracıllğıyla veri kümemizden filtreleme yöntemiyle çıkarmış oluyoruz. Buradaki işlemde tüm kütüphane elemanları RapidMiner yazılımında Türkçe dil desteği olmamasından dolayı Türk Dil Kurumu sözlüğ̈̈nden alınarak kendimiz tarafından oluşturulmuştur. Şekil 3’te belirttiğimiz tüm işlemler tamamlandıktan sonra "Process Documents from Data" operatörü işlemlerini tamamlayarak "WordList to Data" operatörüne filtrelenmiş veri kümesini ileterek tüm kelime parçacıklarını bir yapısal bir veri kümesi olarak oluştururuz. Bu işlemden sonra ise tüm bu yapısal kelime kümesini "Write to Excel P1" operatörünü kullanarak Microsoft Excel olarak kaydederiz ve tüm veri üzerinde oluşturduğumuz analizi görsel olarak sunabiliriz.

Şekil 2'de belirtilen alt satırda oluşturduğumuz diğer bir işlem kümesi de Twitter verileri arasındaki kullanım oranlarını ve tweetlerin hangi oranda retweet edildiğini belirlemek amacıyla oluşturulmuştur. Bu süreçte kullanılan "Aggregate, Sort, Discritize, Write Excel P2" operatörleri kümesel olarak tüm verilerin Twitter kullanıcıları tarafından toplam kullanım oranlarını belirlemektedir. "Aggreagate” operatörü veritabanı uygulamalarında bilinen toplama işlevlerini gerçekleştirmektedir. Bizim veri setimiz üzerinde toplam olarak tweetlerin retweet sayılarının belirlenmesi ve hangi userlar tarafından kaç defa retweetlenme işlemi yapıldığını belirlemektedir. Toplam sayının belirlenmesi ile tüm dağınık veri sayılarını sıralı bir hale dönüştürmek için "Sort" operatörünü kullanarak sıralı bir hale gelen veri setini "Discritize" operatörü vasıtasıyla sıralı ikililer halinde grup haline dönüştürme işlemi yapmaktayız. Tüm veri kümesi son olarak grup arasındaki "Id" kullanımlarının belirlenmesi ve sonrasında Microsoft Excel dosyasına kaydedilmesi için sırasıyla “Aggregate" ve "Write Excel P2” işlemlerini çalıştırır.

\section{Analizlerin Sınıflandırılması ve Değerlendirilmesi}

Şekil 4’te görüldüğü üzere ilk işlem sürecinde elde edilen verilerdeki "Uzaktan Eğitim Proje” ve "Uzaktan Eğitim Test" ölçme değerlendirme değişkenlerinin birlikte kullanıldığı tweetlerdeki en yüksek oranda kullanılan kelime bulutları belirtilmektedir. Kelime bulutlarında bulunan tüm alt birim kelimeleri tweetlerdeki kullanım frekanslarına göre boyutlandırılarak; yüksek frekanslı kelime daha büyük boyutlu, düşük frekanstaki kelime daha küçük boyutta olacak şekilde grafiksel olarak gösterilmektedir. Şekil 4a'da görüldüğü üzere, uzaktan eğitim sürecinde "Proje" bazlı paylaşılmış tweetlerde ortak kullanılan diğer kelimeler "öğretmen, teknoloji, kullanım, örnekler, eğitimde, vb." olarak belirtilirken, Şekil 4b'de uzaktan eğitimde "Test" kelimesiyle birlikte sıkça kullanılan kelimeler “ders, okul, öğrenciler, ödevler, vb.” olarak gözlemlenmektedir. 


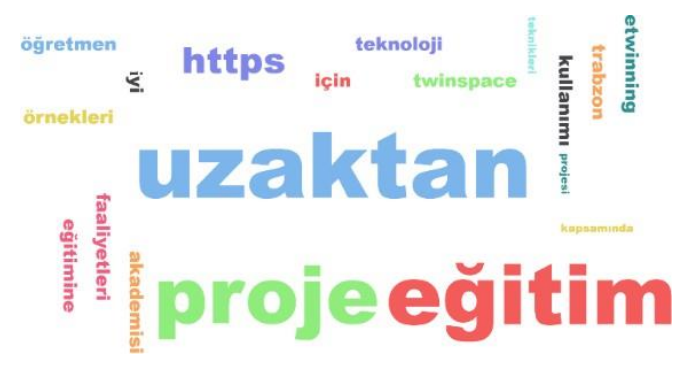

a. Uzaktan Eğitimde Proje Kelime Bulutu

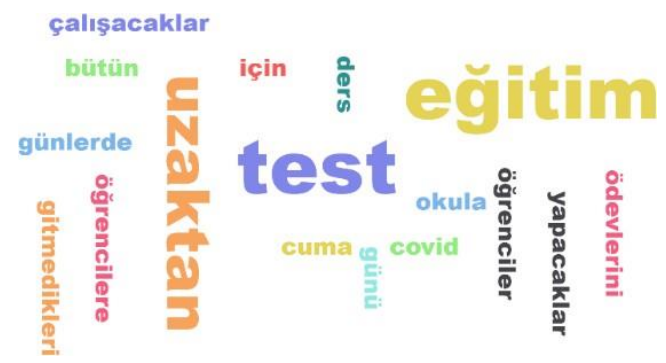

b. Uzaktan Eğitimde Test Kelime Bulutu

Şekil 4. Twitter Uzaktan Eğitim Verilerinde Proje ve Test Ölçme Değerlendirme Değişkenleri

Aynı şekilde uzaktan eğitim sürecinde ölçme ve değerlendirme altyapısında kullanılan "ölçme” ve “değerlendirme” kelimelerinin Twitter paylaşımlarındaki kullanım oranlarını da Şekil 5'te göstermekteyiz. Şekilde görüldüğü üzere uzaktan eğitim sürecinde ölçme ve değerlendirme değişkenlerini incelediğimizde, tweet olarak yapılmış olan paylaşımlardaki ortak kullanılan kelimeler "zenginleştirmek, hazırlık, sürdürülme, sınavlar ve anket” olarak belirtilmektedir. Bu kelimeler arasında uzaktan eğitim sürecinde belirtilen anket değişkeninde uzaktan eğitim ölçme değerlendirme sisteminde yaygın olarak kullanıldığı durumunu ortaya koyabiliriz.

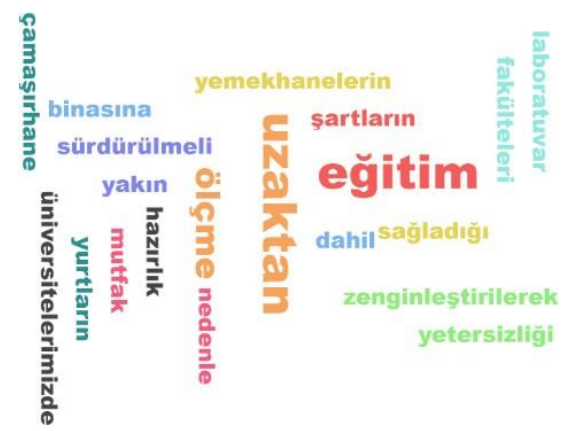

a. Uzaktan Eğitimde Ölçme Kelime Bulutu

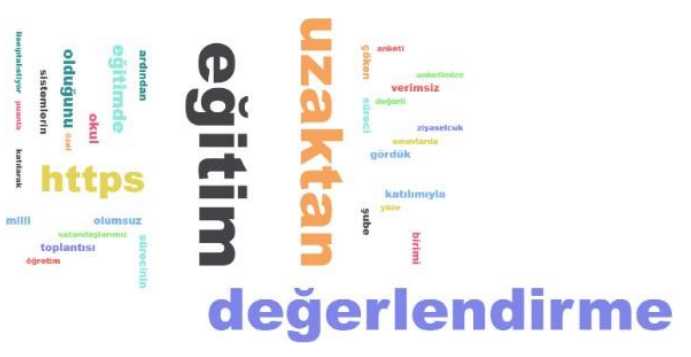

b. Uzaktan Eğitimde Değerlendirme Kelime Bulutu

Şekil 5. Twitter Uzaktan Eğitim Verilerinde Ölçme ve Değerlendirme Değişkenleri Şekil 6'da belirtildiği gibi “anket” kelimesini Twitter'daki uzaktan eğitim ilişkisinin bir ölçme ve değerlendirme değişkeni olarak göz önünde tuttuğumuz takdirde, “üniversite, isteyenler, görüşler, çıktı, sistem, gelişim, vb.” gibi diğer kelimeler ile birlikte sıklıkla kullanıldığını görüyoruz.

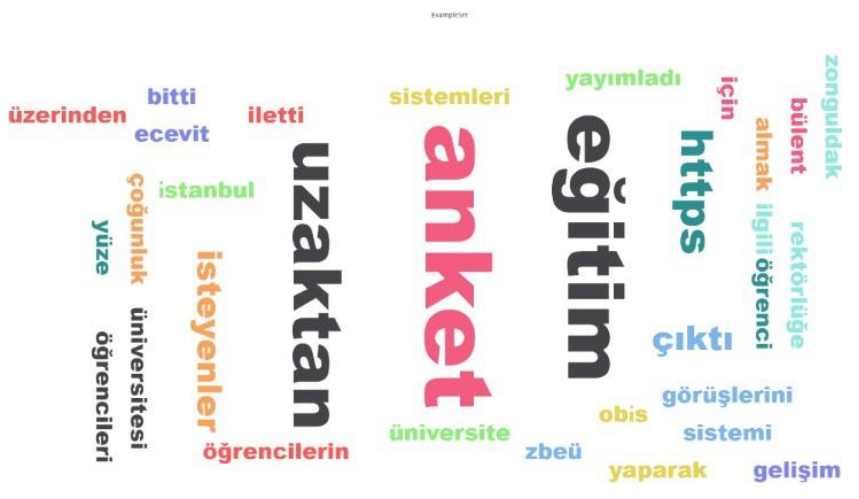

Şekil 6. Twitter Uzaktan Eğitim Verilerinde Anket Değişkeni Kelime Bulutu 
Tüm belirlenen değişkenlerin uzaktan eğitimdeki ölçme ve değerlendirme altyapısına etkisi Twitter'daki kullanım oranları ile doğru orantılı olarak görülmektedir. Şekil 7'de gösterildiği üzere, RapidMiner yazılımında oluşturduğumuz ikinci işlem kümesi aracılığıyla “Id” bazlı verilerin ne kadar retweet edildiğini ve bunların uzaktan eğitim sürecindeki son dönemde etkin rol oynadığını belirtebiliriz. Şekilde de belirtildiği gibi bazı kullanıcıların diğer kullanıcıları uzaktan eğitimde ölçme ve değerlendirme ile alakalı olarak yapmış oldukları paylaşımlarla yüksek oranda etkileyebildiği gözlemlenmektedir.

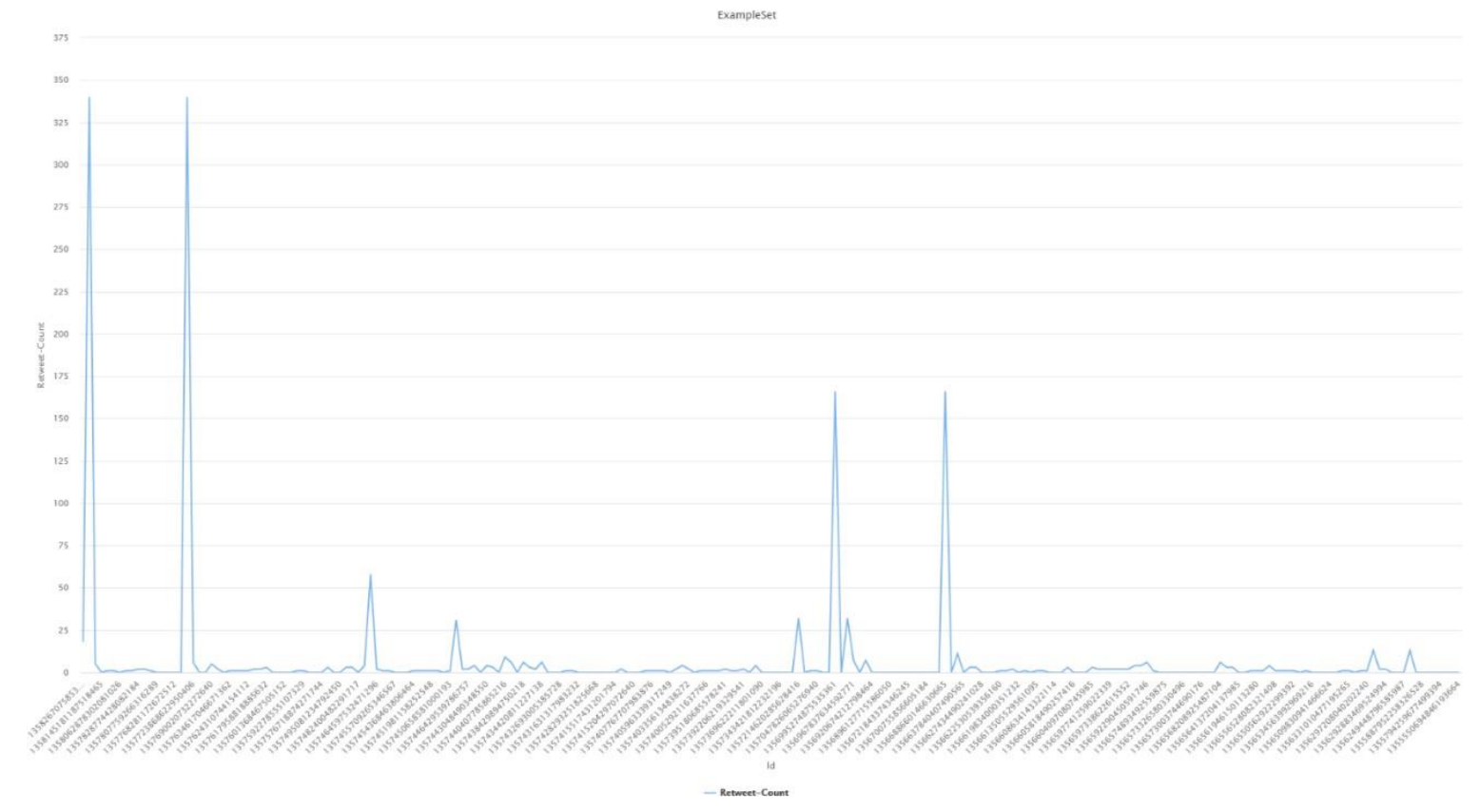

Şekil 7. Twitter'da Paylaşılan Tweetlerin Retweet Edilme Oranları

Aynı zamanda istatistiksel olarak Twitter paylaşımlarında ortak kelimelerin kullanım oranlarını da Şekil 8'de görmekteyiz. Kullanılan kelime birimlerinden "uzaktan eğitim, sınav, lise iptal istiyor, Ziya Selçuk, yüz yüze, ortaokul, online” kelimelerinin yüksek oranda uzaktan eğitim ile alakalı tweetlerde kullanıldığını görmekteyiz. Buna ilave olarak, Şekil 9 tüm uzaktan eğitim ölçme değerlendirme ile alakalı paylaşımlardaki tweetlerdeki gruplandırılmış paylaşımlardaki kelimelerin dağılım oranlarını göstermektedir ve grup olarak (retweet) paylaşım yapılan metinlerde genel olarak "lgselealınsın, sınavlar, yükselme, eşitsizlik, değerlendirme, anlamadığım, sınıf” kelimeleri sıklıkla kullanılmaktadır. Bu grafik bizlere tüm retweet edilmiş veriler arasında uzaktan eğitimdeki eksik veya tamamlanamamış birimleri de belirtmektedir. Twitter platform sayesinde tüm veriler analiz edilerek önceden belirlemiş olduğumuz "uzaktan eğitim ölçme değerlendirme” sorguları aracılığılla kullanıcıların son dönemde paylaştıkları ortak düşünceleri gözlemekteyiz. 


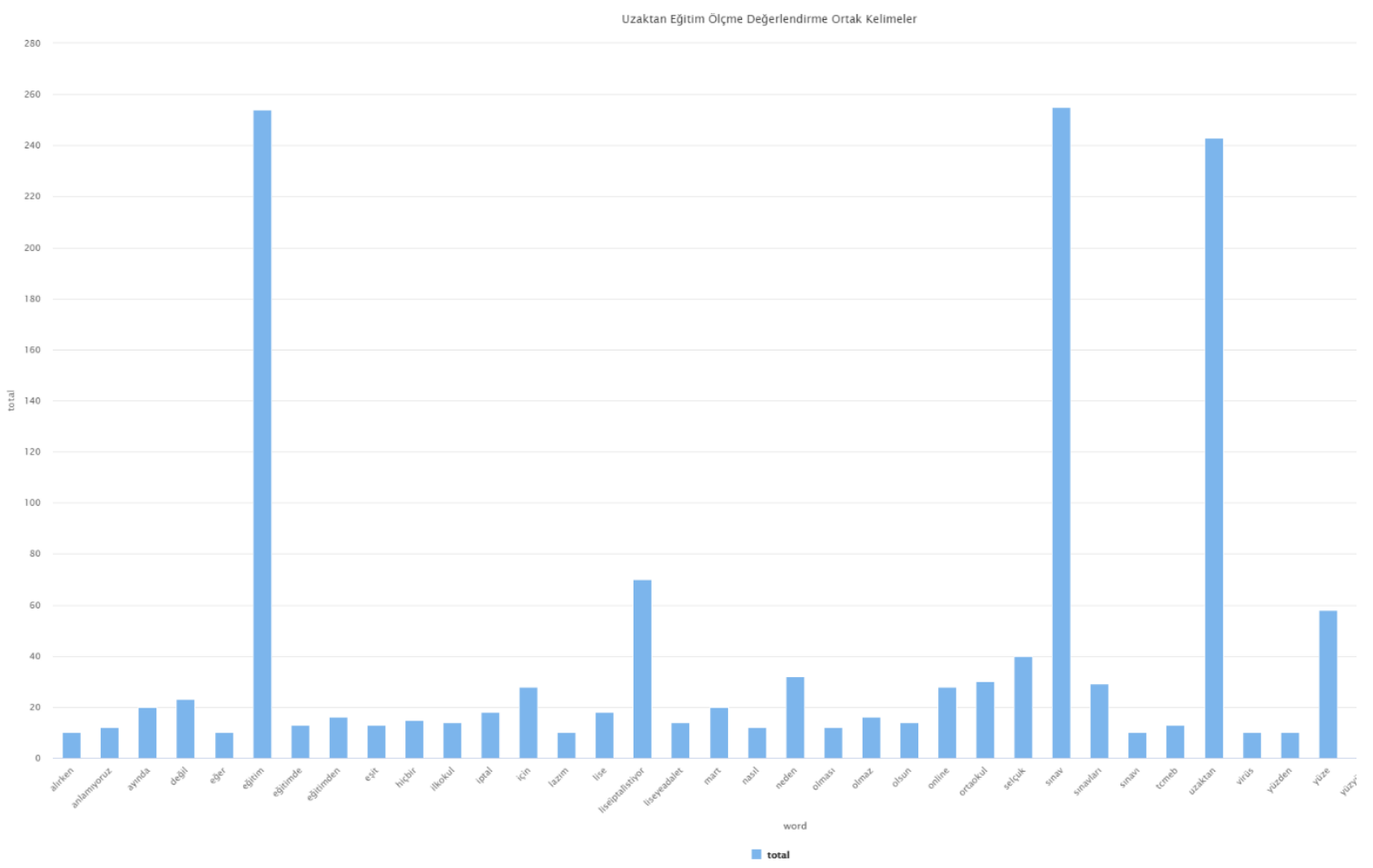

Şekil 8. Twitter'da Paylaşılan Tweetlerdeki Ortak Kullanılan Kelimelerin Kullanılma Oranları

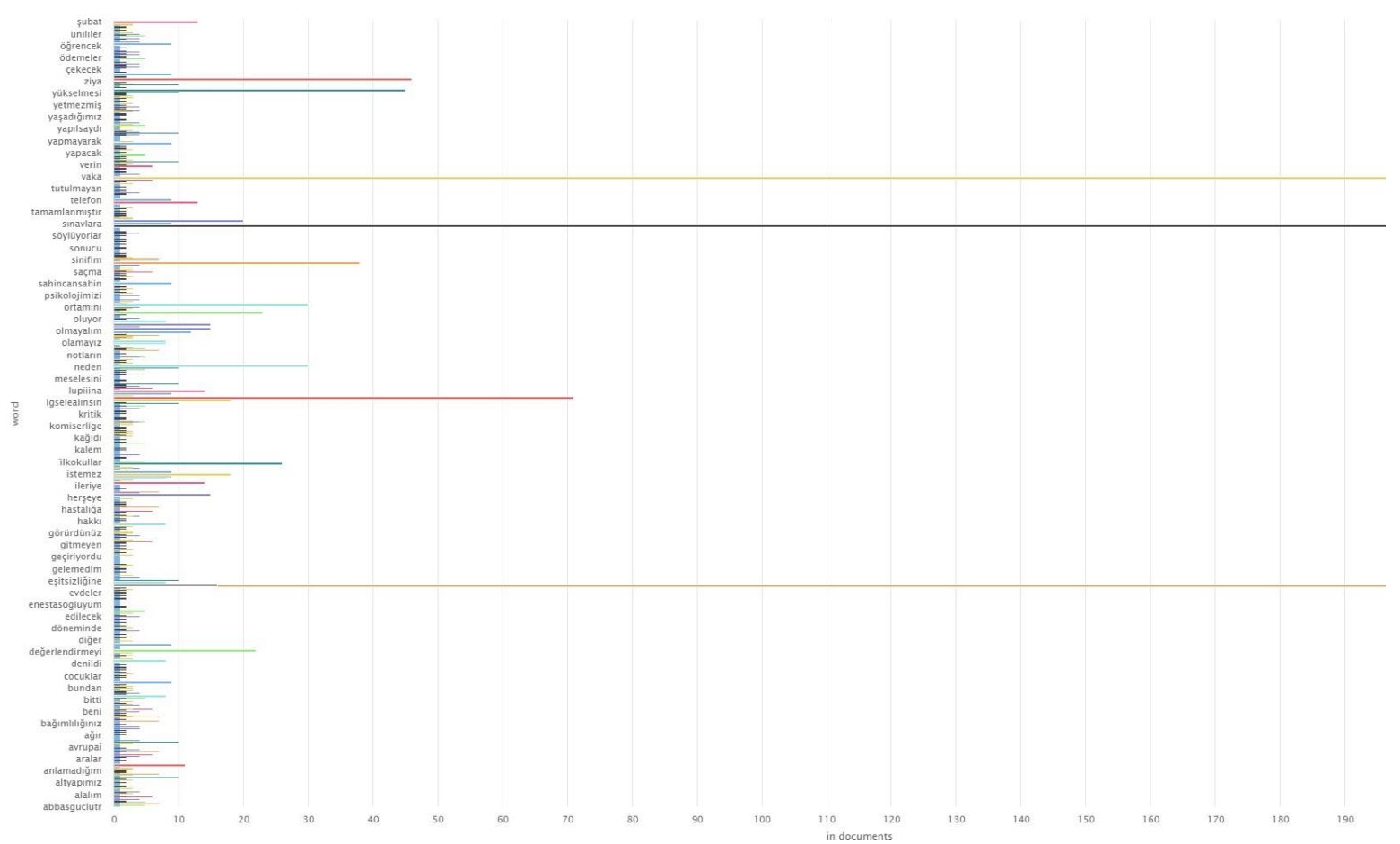

Şekil 9. Twitter'da Paylaşılan Tweetlerdeki Kelimelerin Grup Halinde Paylaşım Oranları 


\section{Sonuç ve Öneriler}

$\mathrm{Bu}$ çalışmada Twitter sosyal medya platformunda pandemi sürecinde uzaktan eğitimde ölçme ve değerlendirme altyapısı hakkında kullanıcılar tarafından oluşturulmuş tweetlerdeki kelimelerin etkisini ve oranlarını RapidMiner veri analizi yazılımı aracılığıyla nasıl gerçekleştirileceği araştırılmıştır. Öncelikle Twitter platformundan istenilen kategorideki verilerin elde edilebilmesi için "Twitter Arama" işlemi kullanılarak tüm işlem adımlarının tanımlanmaları yapılmıştır. Oluşturulan işlemler sonrasında belirlenen uzaktan eğitimdeki ölçme ve değerlendirme değişkenlerinin kullanılan tweetlerdeki kullanım oranlarını gösteren kelime bulutları ve grafikler oluşturulmuştur.

Tüm analizler ve kategorisel veriler ışı̆̆ında, uzaktan eğitimde ölçme ve değerlendirme değişkenlerinden “proje, sınav, online, lise, ortaokul, yüz yüze, vb.” kelime gruplarının tweetlerde kullanım oranlarının yüksek olduğunu ve bu yüksek kullanım oranlarına bağlı olarak uzaktan öğretimdeki ölçme ve değerlendirme altyapısının Twitter platformunda daha çok orta öğretim düzeyinde yaygın olduğunu görebilmekteyiz. Bu nedenle, Twitter paylaşımlarında gözlemlenen bu durum karşısında bazı ölçme değerlendirme altyapılarının belirtilen grafikler sayesinde zayıf olduğu ve birim olarak da yetersizliğinin giderilmesi gerektiği anlaşılmaktadır. Diğer bir deyişle, elde edilen analiz sonuçlarının ve oluşturulan grafik ve kelime bulutlarının uzaktan eğitimdeki ölçme değerlendirme konusunda yaşanılan aksaklık ve eksiklikleri görüp değerlendirme açısından yararlı olacağı düşünülmektedir.

\section{Yayın Etiği Bildirimi / Research Ethics}

Yazar araştırmanın etik dışı bir sorunu olmadığını, araştırma ve yayın etiği konusunu gözlemlediğini beyan etmektedir. / The author declares that the research has no unethical problem, and observe the research and publication ethics.

\section{Araştırmacıların Katkı Oranı / Contribution Rate of Researchers}

Çalışmanın her aşamasına yazar katkı sunmuştur. / The author provide the contribution rates to each stage of the study.

\section{Çıkar Çatışması / Conflict of Interest}

Çalışmada herhangi bir çıkar çatışması bulunmamaktadır. / The study has no conflict of interest.

\section{Fon Bilgileri / Funding}

Bu çalışmada herhangi bir fon kullanılmamıştır. / There is no funding for this study.

\section{Etik Kurul Onayı / The Ethical Commitee Approval}

Etik kurul kararı: Bu araştırma, derleme türünde makale olduğu için etik kurul kararı gerektirmemektedir. / The Ethical Committee Approval: Since this research is a review article, it does not require an ethics committee decision. 


\section{Kaynakça/References}

Adedoyin, O. B., \& Soykan, E. (2020). Covid-19 pandemic and online learning: The challenges and opportunities. Interactive Learning 1-13. https://doi.org/10.1080/10494820.2020.1813180

Anderson, T. (Ed.). (2008). The theory and practice of online learning. Athabasca University Press. https://www.aupress.ca/app/uploads/120146_99Z_Anderson_2008-

Theory and Practice of Online Learning.pdf

Arkorful, V., \& Abaidoo, N. (2015). The role of e-learning, advantages and disadvantages of its adoption in higher education. International Journal of Instructional Technology and Distance Learning, 12(1), 29-42.

Astin, A. W. (2012). Assessment for excellence: The philosophy and practice of assessment and evaluation in higher education. Rowman \& Littlefield Publishers. https://go.exlibris.link/5KyzhzWy

Asur, S., \& Huberman, B. A. (2010). Predicting the future with social media. In 2010 IEEE/WIC/ACM international conference on web intelligence and intelligent agent technology (Vol. 1, pp. 492-499). IEEE.

Bahasoan, A. N., Ayuandiani, W., Mukhram, M., \& Rahmat, A. (2020). Effectiveness of online learning in pandemic COVID-19. International Journal of Science, Technology \& Management, 1(2), 100-106.

Bozkurt, A., \& Sharma, R. C. (2020). Emergency remote teaching in a time of global crisis due to CoronaVirus pandemic. Asian Journal of Distance Education, 15(1), i-vi.

Chick, R. C., Clifton, G. T., Peace, K. M., Propper, B. W., Hale, D. F., Alseidi, A. A., \& Vreeland, T. J. (2020). Using technology to maintain the education of residents during the COVID-19 pandemic. Journal of Surgical Education, 77(4), 729-732.

Das, D. D., Sharma, S., Natani, S., Khare, N., \& Singh, B. (2017). Sentimental analysis for airline twitter data. In IOP Conference Series: Materials Science and Engineering (Vol. 263, No. 4, p. 042067). IOP Publishing.

Dubey, P., \& Pandey, D. (2020). Distance learning in higher education during pandemic: challenges and opportunities. Int. J. Indian Psychol, 8(2), 43-46.

Faizi, R., El Afia, A., \& Chiheb, R. (2013). Exploring the potential benefits of using social media in education. International Journal of Engineering Pedagogy (iJEP), 3(4), 50-53.

Flaherty, C. (2020). Grading for a pandemic. Inside Higher Ed. https://www.insidehighered.com/news/2020/04/23/how-lenient-or-not-should-professors-be-studentsright-now

Hovorka, D., \& Rees, M. J. (2009). Active collaboration learning environments: The class of Web 2.0, 20th Australasian Conference on Information Systems: ACIS 2009, Melbourne, Australia. http://epublications.bond.edu.au/cgi/viewcontent.cgi?article1/41124\&context1/4infotech_pubs

Kunnakorntammanop, S., Thepwuttisathaphon, N., \& Thaicharoen, S. (2019). An experience report on building a big data analytics framework using Cloudera CDH and RapidMiner Radoop with a cluster of commodity computers. In International Conference on Soft Computing in Data Science (pp. 208-222). Springer, Singapore.

Liu, M., Kalk, D., Kinney, L., \& Orr, G. (2012). Web 2.0 and its use in higher education from 2007-2009: A review of literature. International Journal on E-Learning, 11(2), 153-179. 
Osterlind, S. (2002). Constructing Test Items: Multiple-Choice, Constructed-Response, Performance, and Other Formats. New York: Kluwer Academic Publishers. Journal of Educational Measurement Vol. 36, No. 3 (Autumn, 1999), pp. 267-270 (4 pages)

Selwyn, N., \& Stirling, E. (2016). Social media and education now the dust has settled. Learning, media and technology, 41(1), 1-5.

Sherry, L. (1995). Issues in distance learning. International journal of educational telecommunications, 1(4), 337 365.

Sinoplu, M., \& Y1lmaz, R. (2020). Social media analysis in distance education period due to pandemic: data mining application on Twitter data. Journal of Teacher Education and Lifelong Learning, 2(2), 66-76.

Udayakumar, S., Senadeera, D. C., Yamunarani, S., \& Cheon, N. J. (2018). Demographics analysis of twitter users who tweeted on psychological articles and tweets analysis. Procedia computer science, 144, 96-104.

Valentine, D. (2002). Distance learning: Promises, problems, and possibilities. Online journal of distance learning administration, 5(3). 